\title{
Salvia divinorum Epling \& Játiva (Maria Pastora) e Salvinorina A: crescente uso recreacional e potencial de abuso
}

\author{
SCHNEIDER, R.J. ${ }^{1 *}$; ARDENGHI, P. ${ }^{2}$ \\ ${ }^{1}$ Centro Universitário Feevale, Instituto de Ciências da Saúde, Biomedicina, RS-239 2755 , CEP: 93352-000, \\ Novo Hamburgo-Brasil *quimtox@gmail.com, ${ }^{2}$ Instituto de Ciências da Saúde, Grupo de Pesquisa em Saúde \\ Humana e Ambiente, RS-239 2755, CEP: 93352-000, Novo Hamburgo-Brasil
}

\begin{abstract}
RESUMO: A planta Salvia divinorum Epling \& Játiva (SDI), da família Lamiaceae, tem sido usada por séculos pela cultura mazateca e vem ganhando popularidade como droga recreacional nos últimos anos. Seu princípio ativo - Salvinorina A (SA) - é agonista dos receptores opióides kappa, com potencial psicotrópico. A utilização da planta vem crescendo na Europa e na América do Norte, apesar de ainda não existirem provas concretas sobre abuso. A presente revisão da literatura contemporânea aborda as evidências sobre o potencial de abuso de SDI, bem como o crescente uso recreacional, ainda que seja alucinógeno permitido legalmente e de fácil compra em muitos países.
\end{abstract}

Palavras-chave: Salvia divinorum, Salvinorina A, potencial de abuso, uso recreacional

\begin{abstract}
Salvia divinorum Epling \& Játiva ("ska María Pastora") and Salvinorin A: increasing recreational use and abuse potential. The plant Salvia divinorum Epling \& Játiva (SDI), of the Lamiaceae family, has been used for centuries by the Mazateca culture and has gained popularity as a recreational drug in the last years. Its active principle, Salvinorin $A(S A)$, is a potentially psychotropic agonist of the kappa opioid receptors. The use of SDI has increased in Europe and North America, although there are no concrete proofs about abuse. The present review discusses current evidence on potential SDI abuse, as well as its increasing recreational use, although it is considered a legalized hallucinogen easily acquired in many countries.
\end{abstract}

Key words: Salvia divinorum, Salvinorin A, abuse potential, recreational use

A planta Salvia divinorum (SDI), da família Lamiaceae, tem sido usada por séculos pela cultura mazateca (Wolowich et al., 2006) e vem ganhando popularidade como droga recreacional nos últimos anos (Chavkin et al., 2004; Grundmann et al., 2007). É uma erva perene, natural da serra mazateca de Oxaca, no México (Vortherms \& Roth, 2006; Valdes, 1994). Nomes comuns para a sálvia são "ska Maria Pastora" e "La Maria", refletindo a crença mazateca de que a sálvia é a encarnação da Virgem Maria (Vortherms \& Roth, 2006).

Os potentes efeitos alucinógenos, descritos em relatos de caso, estimularam estudos que identificaram o primeiro agonista opióide kappa altamente seletivo não-nitrogenado a salvinorina $A(S A)$ (Grundmann et al., 2007). Esta substância parece ser "alucinógeno por excelência" (Valdes, 1994), produzindo efeitos psicotrópicos apenas pela estimulação do receptor opióide kappa (González et al., 2006; Prisinzano, 2005; Babu et al., 2008), com afinidade muito pouco significativa pelos receptores opióides mu (Wang et al., 2004; Rothman et al., 2007) e kappa do tipo 2 (Ansonoff et al., 2006) e sem ação sobre receptores serotoninérgicos do tipo $2 \mathrm{~A}$ (González et al., 2006; Prisinzano, 2005; Babu et al., 2008).

O diterpeno SA, agonista kappa opióide de alta afinidade (Chavkin et al., 2004; Roth et al., 2002), tem potencial psicotrópico similar ao da mescalina (Giroud et al., 2000), porém com diferentes efeitos (Braida et al., 2007). Tem baixa biodisponibilidade oral, o que motivou a pesquisa de análogos como a $\mathrm{N}$-metilacetamida (Béguin et al., 2007).

Tradicionalmente a SDI tem sido mascada sob forma de folhas frescas ou ingerida como bebida que contém extrato das folhas maceradas. De modo alternativo, é consumida por inalação de fumaça obtida pela queima da folha (Vortherms \& Roth, 2006).

Recebido para publicação em 13/11/2008

Aceito para publicação em 19/02/2010

Rev. Bras. Pl. Med., Botucatu, v.12, n.3, p.358-362, 2010. 
Trabalhos mostram que $61,4 \%$ das pessoas usam o extrato concentrado da SDI, enquanto $37,3 \%$ empregam as folhas secas (Baggot et al., 2004). Dependendo da sensibilidade individual de cada usuário e da quantidade de substância usada, os efeitos decorrentes do emprego de SA podem variar de leves a profundos (Siebert, 2004), compreendendo sinestesias, como sentir cheiros que remetem a sons ou ouvir sons que remetem a cores (Babu et al., 2008).

Apesar de ser menos usada, o interesse pela SDI tem aumentado entre usuários recreacionais na Europa e na América do Norte, por modificar o estado de consciência (González et al., 2006) por meio do efeito alucinógeno. Acresce que há facilidade de compra e não se referem efeitos adversos com o uso recreacional. No entanto, há potencial de tolerância, já que a dose parece ter de ser aumentada para conseguir os mesmos efeitos anteriores (Grundmann et al., 2007).

A atual falta de informação sobre SA e SDI e o crescente uso informal trazem a necessidade de conhecimento sobre o potencial de abuso. Autores consideram o uso da planta e do princípio ativo como possível problema de saúde pública na Europa, que deve ser levado em consideração quando se tratam pessoas jovens por abuso de drogas (Bucheler et al., 2005).

\section{Mecanismo de ação da Salvinorina A e relação com potencial de abuso}

Os receptores opióides compreendem quatro tipos, $\mu$ - mu, $\delta$ - delta, $\kappa$ - kappa e nociceptina/ orfanina $F Q(N / F Q)$, cada um com distribuição anatômica única em cérebro, medula espinhal e tecidos periféricos. Em 2000, o Committee on Receptor Nomenclature and Drug Classification of the International Union of Pharmacology adotou os termos MOP, DOP, KOP e NOP para indicar, respectivamente, aqueles receptores. Adicionalmente, vários subtipos têm sido descritos - epsilon, iota, lambda e zeta. O receptor KOP diferencia-se dos demais por genes e proteínas distintos, padrões de expressão tecidual, propriedades funcionais e perfis farmacológicos de agonistas e antagonistas seletivos (Lee et al., 2005).

A ativação de KOP in vivo causa analgesia, disforia, elevação corticoesteróide, diurese (Wang et al., 2004; Lee et al., 2005) e hipotermia (Ansonoff et al., 2006), porém não determina depressão respiratória (Babu et al., 2008).

O sistema opióide endógeno exerce efeitos opostos sobre a atividade dopaminérgica mesolímbica e processos motivacionais. Por exemplo, a ativação de receptores mu na área tegmental ventral estimula a liberação de dopamina no núcleo accumbens e produz estados de preferência condicionados por um ambiente associados à administração de um agonista. Por outro lado, a ativação de KOP no circuito mesolímbico diminui o estímulo neuronal dopaminérgico e inibe a liberação de dopamina no núcleo accumbens (Doyon et al., 2006). O sistema mesolímbico dopaminérgico contribui de maneira muito importante para o desenvolvimento de necessidade de reforço em relação a alimentos, comportamento sexual e drogas de abuso (Carlezon et al., 2006).

Classicamente a "hipótese dopaminérgica" tem sido usada para explicar adição e dependência de substâncias (Prisinzano et al., 2005). SA e outros agonistas kappa-opióides diminuem significativamente os níveis basais de dopamina, assim como impedem o aumento dos níveis dopaminérgicos (Prisinzano et al., 2005). Pesquisa-se o uso de agonistas seletivos de KOP no tratamento da dependência por estimulantes (Prisinzano et al., 2005; Chefer et al., 2005). Parece também atuar como eficiente bloqueador do efeito de recompensa provocado por morfina (Narita et al., 2005), levando em conta que o KOP participa da expressão da síndrome de abstinência crônica induzida por aquele opióide (Lee et al., 2005).

O fato da Salvinorina A diminuir níveis de dopamina estriatal e produzir aversão em ratos sugere que isso poderia acontecer com humanos. Entretanto, numerosos estudos têm encontrado compostos que produzem efeitos adversos em roedores, porém em humanos induzem auto-administração (Zhang et al., 2005). Além disso, SA parece ter mecanismos farmacológicos diferentes de agonistas kappaopióides sintéticos sobre a função dopaminérgica (Gehrke \& Chefer, 2008) e parece ligar-se ao KOP diferentemente dos ligantes tradicionais (Tidgewell et al., 2006). Outros estudos têm mostrado que outro sistema, o endocanabinóide, parece estar envolvido no processo de abuso pelo SA.

Há trabalhos que sugerem atuação da SA não somente em KOP, mas também em receptores canabinóides tipo 1, tendo em vista que o antagonista canabinóide rimonabanto reverteu os efeitos de reforço induzido por SA (Braida et al., 2007). Em estudos posteriores realizados em ratos, confirmou-se potencial de reforço de SA, mesmo em doses muito baixas (Braida et al., 2008). Uma inferência químicoestrutural também pode ser feita, na medida em que tanto SA quanto delta-9-tetraidrocanabinol são terpenóides (Figura 1) e possuem aparentemente 0 mesmo perfil farmacológico (Braida et al., 2007).

\section{Abuso por Salvia divinorume Salvinorina A}

Apesar de a disponibilidade da planta SDI crescer, são escassos os estudos sobre os efeitos psicológicos e potencial de abuso (Appel \& Appel, 2007). O mesmo acontece com SA. Artigos relatam que ainda não foi evidenciado potencial de abuso pelo uso isolado de SA ou extrato da SDI (Mccurdy, 2006). 


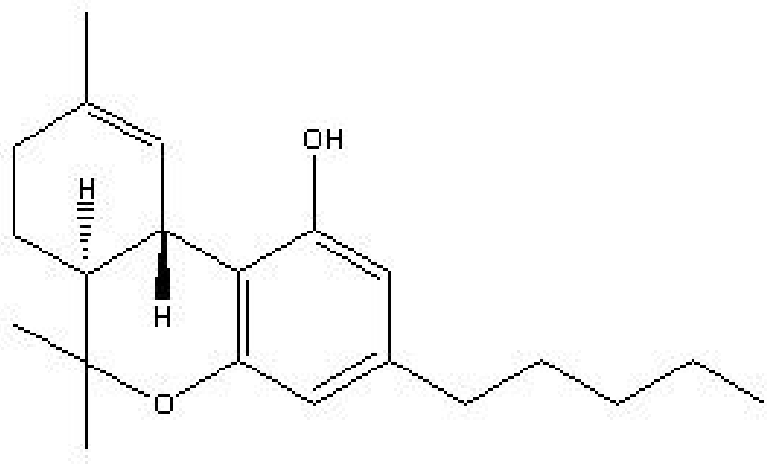

Tetrahidrocanabinol

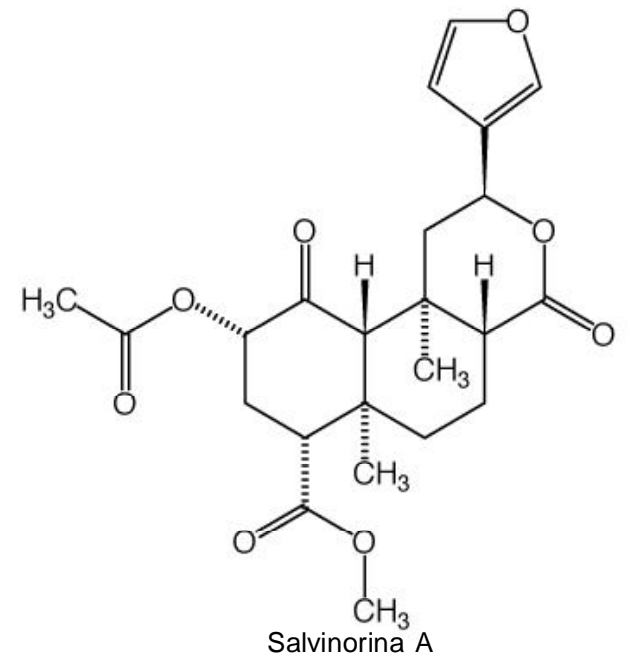

Salvinorina A

FIGURA 1. Estrutura de dois terpenóides de mesmo perfil farmacológico (Tetrahidrocanabinol e Salvinorina A).

Porém já existem alguns dados disponíveis sobre padrões de uso e abuso dessas substâncias (Braida et al., 2008). O envolvimento e a conscientização sobre a SDI têm crescido contemporaneamente (González et al., 2006).

Consequências médicas ou psicológicas negativas relacionadas ao uso da Salvia são escassas na literatura científica (Lange et al., 2007). Aparentemente existe apenas um relato de caso sobre consequências negativas do uso da SDI (Singh, 2007).

Alguns usuários reportam sintomas de fadiga, exaustão e letargia após o uso da SDI (Hoover et al., 2007). Sugere-se que tais manifestações expressam a habilidade da SA em produzir efeitos psicotomiméticos ou alucinógenos em humanos, os quais podem ser prazerosos para algumas pessoas (Zhang et al., 2005).

Pode-se prever crescimento rápido do uso abusivo de SDI e SA (Prisinzano, 2005). Apenas um levantamento epidemiológico define perfil de idade e gênero para o primeiro uso da SDI e o consumo no último mês, no norte da ltália (Tabela 1) (Pavarin, 2006). De 2015 jovens entrevistados, $11 \%$ consumiam a SDI. Outro estudo americano aponta que $4,4 \%$ das pessoas usaram SDI nos últimos 12 meses em amostra de 1516 estudantes americanos (Lange et al., 2007). Aparentemente não há registros de estudos epidemiológicos sobre o uso da SDI no Brasil.
A SDI vem chamando a atenção também dos usuários recreacionais (Appel \& Appel, 2007). Mais recentemente, extratos de SDI e SA têm sido usados em vários países como Suíça, México e Estados Unidos (em alguns Estados) como alucinógeno legal (Lange et al., 2007; Giroud et al., 2000; Roth et al., 2002). É proibido o uso e venda em países como Dinamarca, Austrália e Itália (Prisinzano, 2005). Recentemente, o Japão colocou SA e SDI na lista de produtos e substâncias ilegais (Hanajiri et al., 2008). No Brasil, aparentemente a SDI continua legalmente permitida e fora da lista de plantas controladas pela ANVISA.

Já existem métodos laboratoriais eficientes para dosagem do SA em fluidos biológicos através de cromatografia gasosa e espectrometria de massa (Pichini et al., 2005). Entretanto, tais técnicas não são empregadas para triar o uso entre a população.

\section{A Internet como ferramenta de fácil compra e incentivo}

De acordo com o U.S Government Accountability Office, a Internet é o veículo mais amplamente usado para obtenção de drogas controladas (Hoover et al., 2007). Outros estudos também mostram a Internet como nova e crescente ferramenta de busca por drogas e troca de informações sobre as mesmas (Siemann et al., 2006). Muitos sites estão dedicados a SDI, com dados relativos à

TABELA 1. Média de idade e sexo de indivíduos que consumiram Salvia divinorum no último mês e como primeiro uso no norte da Itália (Pavarin, 2006).

\begin{tabular}{lllll}
\hline \multirow{2}{*}{ Salvia divinorum } & \multicolumn{2}{c}{ Consumo no último mês } & \multicolumn{2}{c}{ Primeiro uso } \\
& Feminino & Masculino & Feminino & Masculino \\
\cline { 2 - 5 } & 20,1 anos & 22,4 anos & 19,7 anos & 20,4 anos \\
\hline
\end{tabular}


botânica, etnobotânica, bioquímica e farmacologia da SDI, como http://salvia.lycaeum.org/ott.html e http:// salvia.com/salvia (Giroud et al., 2000).

A SDI tem sido comprada em tabacarias nos Estados Unidos e em sites de compra de cunho generalista, por exemplo, eBay.com (Lange et al., 2007), ou ainda em sites de suplementos alimentares (González et al., 2006). Mais de três quartos dos sites sobre a SDI encorajam o uso da planta e poucos deles apóiam o não-uso, provendo informações sobre cuidados ou alertas (Hoover et al., 2007).

Assim como a maconha, a SDI também pode ser cultivada domesticamente ou em qualquer ambiente úmido de clima semitropical (Hoover et al., 2007). Este fato contribui também para a acessibilidade da planta por boa parte das pessoas.

\section{CONCLUSÃO}

- É fato que o uso da SDI tem realmente crescido nos últimos tempos, de forma ainda legal em muitos países.

- É especialmente preocupante que a maioria dos sites na Internet esteja explorando a relativa escassez de dados sobre a SDI como evidência para o consumo seguro ou a ausência de restrições para o uso.

- São escassos os estudos sobre dependência envolvendo a SDI ou o SA. Há falta de dados toxicológicos consistentes relativos ao uso crônico de SA. Isso configura a impossibilidade de fazer afirmativas consistentes sobre potencial de abuso e segurança com uso da planta e de seu princípio ativo.

- Apesar de já existirem técnicas padronizadas para detecção e monitoramento biológico do princípio ativo e dos metabólitos em fluidos biológicos, aquelas deveriam ser implementadas para servir como biomarcadores da exposição.

- Mais estudos precisam ser feitos para definir o uso da SDI e do princípio ativo como possível problema de saúde pública em nível mundial.

- No Brasil, ainda não existem dados epidemiológicos ou relatos de caso clinicamente relevantes sobre o uso recreacional desta planta.

\section{REFERÊNCIA}

ANSONOFF, M.A. et al. Antinociceptive and hypothermic effects of Salvinorin A are abolished in a novel strain of kOpioid receptor-1knockout mice. The Journal of Pharmacology and Experimental Therapheutics, v.318, n.2, p.641-8, 2006.

APPEL, J.; APPEL, D.K. The rise of a new psychoactive agent: Salvia divinorum. International Journal of Mental Health Addiction, v.5, n.3, p.248-53, 2007.

BABU, K.M.; MCCURDY, C.R.; BOYER, E.W. Opioid receptors and legal highs: Salvia divinorum and kratom. Clinical Toxicology, v.46, n.2, p.146-52, 2008.

BAGGOTT, M.J. et al. Use of Salvia divinorum, an unscheduled hallucinogenic plant: a web-based survey of 500 users. Clinical Pharmacology Therapheutics, v.75, n.2, p.72, 2004.

BÉGUIN, C. et al. $N$-methylacetamide analogue of salvinorin $A$ : a highly potent and selective kappa opioid receptor agonist with oral efficacy. American Society for Pharmacology and Experimental Therapheutics, v.324, n.1, p.188-95, 2007.

BRAIDA, D. et al. Hallucinatory and rewarding effect of salvinorin A in zebrafish: k-opioid and CB1-cannabinoid receptor involvement. Psychopharmacology, v.190, n.4, p.441-8, 2007.

BRAIDA, D. et al. Involvement of k-Opioid and endocannabinoid system on salvinorin $A$ induced reward. Biological Psychiatry, v.63, n.3, p.286-92, 2008.

BUCHELER, $R$. et al. Use of nonprohibited hallucinogenic plants: Increasing relevance for public health? A case report and literature review on the consumption of Salvia divinorum (Diviner's sage). Pharmacopsychiatry, v.38, n.1, p.1-5, 2005.

CARLEZON, W.A. et al. Depressive-like effects of the kOpioid receptor agonist salvinorin $A$ on behavior and neurochemistry in rats. The Journal of Pharmacology and Experimental Therapheutics, v.316, n.1, p.440-7, 2006.

CHAVKIN, C. et al. Salvinorin A, an active component of the hallucinogenic sage Salvia divinorum is a highly efficacious k-Opioid receptor agonist: structural and functional considerations. The Journal of Pharmacology and Therapheutics, v.308, n.3, p.1197-203, 2004.

CHEFER, V.L. et al. Endogenous k-Opioid receptor systems regulate mesoaccumbal dopamine dynamics and vulnerability to cocaine. Journal of Neuroscience, v.25, n.20, p.5029-37. 2005

DOYON, W.M. et al. k-Opioid receptor modulation of accumbal dopamine concentration during operant ethanol self-administration. Neuropharmacology, v.51, n.3, p.487-96, 2006.

GEHRKE, B.J.; CHEFER, V.L. Effects of acute and repeated administration of salvinorin $A$ on dopamine function in the rat dorsal striatum. Psychopharmacology, v.197, n.3, p.509-17, 2008.

GIROUD, C. et al. Salvia divinorum: a hallucinogenic mint which might become a new recreational drug in Switzerland. Forensic Science International, v.112, n.2, p.143-50, 2000.

GONZÁLEZ, D. et al. Pattern of use and subjective effects of Salvia divinorum among recreational users. Drug and Alcohol Dependence, v.85, n.2, p.157-62, 2006.

GRUNDMANN, O. et al. Salvia Divinorum and Salvinorin A: An update on pharmacology and analytical methodology. Planta Medica, v.73, n.10, p.1039-46, 2007.

HANAJIRI, R.K. et al. Analytical data of designated substances controlled by the pharmaceutical affairs law in Japan. Yakugaku Zasshi, v.128, n.6, p.971-9, 2008.

HOOVER, V. et al. Internet access to Salvia divinorum: Implications for policy, prevention, and treatment. Journal of Substance Abuse Treatment, v.35, n.1, p.22-7, 2007. LANGE, J.E. et al. College student use of Salvia divinorum. Drug Alcohol Dependence, v.94, n.1, p.2636, 2007. 
LEE, D.Y.W. et al. New neoclerodane diterpenoids isolated from the leaves of Salvia divinorum and their binding affinities for human k-opioid receptors. Bioorganic \& Medicinal Chemistry, v.13, n.19, p.5635-9, 2005.

MCCURDY, C.R. et al. Antinociceptive profile of salvinorin A, a structurally unique kappa opioid receptor agonist. Pharmacology, Biochemistry and Behavior, v.83, n.1, p.109-13, 2006.

NARITA, M. et al. Direct evidence for the involvement of the mesolimbic k-Opioid system in the morphine-induced rewarding effect under an inflammatory pain-like state. Neuropsychopharmacology, v.30, n.1, p.111-8, 2005.

PAVARIN, R.M. Substance use and related problems: a study on the abuse of recreational and not recreational drugs in Northern Italy. Annalli dell'Istituto Superiori di Sanità, v.42, n.4, p.477-84, 2006.

PICHINI, S. et al. Quantification of the plant-derived hallucinogen Salvinorin $A$ in conventional and nonconventional biological fluids by gas chromatography/mass spectrometry after Salvia divinorum smoking. Rapid Communications in Mass Spectrometry, v.19, n.12, p.1649-56, 2005.

PRISINZANO, T.E.; TIDGEWELL, K.; HARDING, W.W. kOpioids as potential treatments for stimulant dependence. American Association of Pharmaceutical Scientists Journal, v.7, n.3, p.592-9, 2005.

PRISINZANO, T.E. Psychopharmacology of the hallucinogenic sage Salvia divinorum. Life Sciences, v.7, n.3, p.527-31, 2005.

ROTH, B.L. et al. Salvinorin A: A potent naturally occurring nonnitrogenous k-opioid selective agonist. Proceedings of The National Academy of Science of The United States of America, v.99, n.18, p.11934-9, 2002.

ROTHMAN, R.B. et al. Salvinorin A: allosteric interactions at the k-opioid receptor. The Journal of Pharmacology and Experimental Therapheutics, v.320, n.2, p.801-10, 2007.

SIEBERT, D.J. Localization of Salvinorin A and related compounds in glandular trichomes of the psychoactive sage, Salvia divinorum. Annals of Botany, v.93, n.6, p.763-71, 2004.

SIEMANN, $H$. et al. Salvia divinorum representation of a new drug in the Internet. Gesundheitswesen, v.68, n.5, p.323-7, 2006.

SINGH, S. Adolescent salvia substance abuse. Addiction, v.102, n.5, p.823-4, 2007.

TIDGEWELL, K. et al. Synthesis of Salvinorin A analogues as opioid receptor probes. Journal of Natural Products, v.69, n.6, p.914-8, 2006.

VALDÉS, L.J. Salvia divinorum and the unique diterpene hallucinogen, Salvinorin (Divinorin) A. Journal of Psychoactive Drugs, v.26, n.3, p.277-83, 1994.

VORTHERMS, T.A.; ROTH, B.L. Salvinorin A: from natural product to human therapeutics. Molecular Interventions, v.6, n.5, p.257-65, 2006.

WOLOWICH, W.R. et al. Analysis of the psychoactive terpenoid Salvinorin A content in five Salvia divinorum herbal products. Pharmacotherapy, v.26, n.9, p.126872, 2006.

WHANG, Y. et al. Comparison of pharmacological activities of three distinct k-ligands (Salvinorin A, TRK820 and 3FLB) on k-opioid receptors in vitro and their antipruritic and antinociceptive activities in vivo. The Journal of Pharmacology and Experimental Therapheutics, v.312, n.1, p.220-30, 2004.

ZHANG, Y. et al. Effects of the plant-derived hallucinogen salvinorin $A$ on basal dopamine levels in the caudate putamen and in a conditioned place aversion assay in mice: agonist actions at kappa opioid receptors. Psychopharmacology, v.179, n.3, p.551-8, 2005. 